\title{
Infiltration of liquid water in an acid-leached zeolite
}

\author{
Aijie Han and Yu Qiao ${ }^{\text {a) }}$ \\ Department of Structural Engineering, University of California-San Diego, \\ La Jolla, California 92093-0085
}

(Received 30 July 2007; accepted 20 September 2007)

Through acid-leaching treatment, the degree of hydrophobicity of a zeolite $\beta$ can be controlled in a broad range. As the treatment time increases, the nanopore surface can change from hydrophilic to hydrophobic, leading to the formation of an infiltration plateau in sorption isotherm curve. The infiltration pressure and hysteresis are dependent on the testing temperature. As temperature rises, the effective degree of hydrophobicity is lowered, while the defiltration is much more pronounced.

\section{INTRODUCTION}

Controlling liquid motion in nanochannels, nanotubes, and nanopores is of important relevance to drug delivery, ${ }^{1}$ purification and mixture separation, ${ }^{2}$ and adsorption, ${ }^{3}$ as well as energy absorption and volume control. ${ }^{4,5}$ Over the years, a number of techniques were developed based on electrical, ${ }^{6}$ thermal, ${ }^{7}$ or mechanical ${ }^{8}$ methods. For instance, by maintaining a pressure difference, a liquid can penetrate through a nanoporous membrane ${ }^{9}$ or a carbon nanotube cluster. ${ }^{10}$ Recently, pressure-induced infiltration technique was investigated to actuate liquid flow in energetically unfavorable nanoenvironment. ${ }^{11,12}$ In a nanoporous material, if the nanopore wall is hydrophobic, a high quasi-static pressure needs to be applied on the liquid phase; otherwise, the liquid cannot overcome the capillary effect. As the pressure is lowered, the confined liquid may either be "locked" inside ${ }^{13,14}$ or defiltrate out of the nanopores. ${ }^{15,16}$ The former phenomenon can be used in advanced protective systems, such as car bumpers and blast-resistant containers, and the latter provides a promising mechanism for developing liquid springs or actuators.

One of the most commonly applied nanoporous materials is zeolite. ${ }^{17}$ Zeolites or zeolitelike materials can be of various degrees of crystallinity. The pore size is smaller than $2 \mathrm{~nm}$, since the framework channel is usually composed with 8 to 20 oxygen member rings. Very often, the porosity is around $0.2 \mathrm{~cm}^{3} / \mathrm{g}$ and the nanopores are interconnected. A dominant factor affecting its surface property is the surface defect density. The surface defects can be formed by silanol groups or Lewis acid sites. They are catalytically active and/or chemically reactive. If there are a relatively large number of defects,

\footnotetext{
a) Address all correspondence to this author.

e-mail: yqiao@ucsd.edu

DOI: 10.1557/JMR.2007.0446
}

the material is quite polar and thus is wettable to water. Under this condition, as the zeolite is immersed in water it can be soaked spontaneously. If the defect density is relatively small, the surface tends to be nonpolar, and hence the material can be hydrophobic. Note that as the zeolite is immersed in liquid water, its nominal degree of hydrophobicity is lower than in vapor. In a gas absorption analysis, when the silica-to-alumina $(\mathrm{Si} / \mathrm{Al})$ ratio is higher than 18 , the material is usually regarded as hydrophobic; while in a pressure-induced infiltration experiment, the silica-to-alumina ratio must be much larger; otherwise no infiltration can be detected. ${ }^{18}$

Synthesizing low-defect-density zeolite is a nontrivial task. ${ }^{19}$ To decrease the density of surface defects, aluminum content in the framework needs to be lowered, which imposes tremendous challenges in precise control of nanopore structure. One way to solve this problem is to first produce a zeolite of relatively high defect density and then modify its surface structure through chemical treatment, such as acid leaching. ${ }^{20}$ By using a mineral acid, aluminum atoms from the framework of a zeolite can be removed, and thus pre-existing defects are healed and a higher $\mathrm{Si} / \mathrm{Al}$ ratio is reached. As the polarity of nanopore surface is lowered, the wettability decreases and the sorption properties can be adjusted.

In the current study, the acid-leaching technique is used to adjust the surface structure of a zeolite $\beta .^{21}$ It is validated that by controlling the treatment time, the wetting-nonwetting transition can be detected during the pressure-induced infiltration process; that is, if the acidleaching treatment is sufficiently long, the material can change from hydrophilic to hydrophobic. It is also noticed that the sorption isotherm is thermally dependent.

\section{EXPERIMENTAL}

The material under investigation was a Zeolyst CP811E-75B zeolite. Its nanoporous structure was characterized via a gas absorption analysis. By using a 
Tristar-3000 (Gemini, The Netherlands) analyzer, the specific surface area was measured as $550 \mathrm{~m}^{2} / \mathrm{g}$, and the specific micropore volume was $270 \mathrm{~mm}^{3} / \mathrm{g}$. The material was well crystallized. The framework contained threedimensional 12-ring channels with pore diameters of $0.55 \mathrm{~nm} \times 0.55 \mathrm{~nm}$ and $0.76 \mathrm{~nm} \times 0.64 \mathrm{~nm}$. The asreceived material was in powder form, with the average particle size of about $20 \mu \mathrm{m}$. In a round-bottom flask, $1.0 \mathrm{~g}$ of zeolite was mixed with $100 \mathrm{~mL}$ of $13 \mathrm{~mol} / \mathrm{L}$ aqueous solution of nitric acid when the solution was slowly stirred. The mixture was refluxed at $80{ }^{\circ} \mathrm{C}$. The treatment time ranged from 3 to $24 \mathrm{~h}$. After refluxing, the sample was cooled in air. The dealuminated zeolite $\beta$ powders were collected by vacuum filtering and then washed repeatedly in distilled water. They were dried in air at $70{ }^{\circ} \mathrm{C}$ and calcined at $580{ }^{\circ} \mathrm{C}$ in a nitrogen flow for $10 \mathrm{~h}$. After the acid-leaching treatment, the specific micropore volume became $320 \mathrm{~mm}^{3} / \mathrm{g}$, indicating that alumina sites were removed.

The pressure-induced infiltration experiment was performed using a high-pressure stainless steel chamber, which contained $0.5 \mathrm{~g}$ of acid-leached zeolite $\beta$ sample and $6 \mathrm{~g}$ of deionized water. A quasi-hydrostatic pressure was applied on the liquid phase through a piston. The cross-sectional area of the piston was $A_{0}=286 \mathrm{~mm}^{2}$. The piston was compressed by a type-5569 Instron (Norwood, MA) machine into the steel chamber at the rate of $1 \mathrm{~mm} / \mathrm{min}$. When the pressure inside the chamber exceeded about $50 \mathrm{MPa}$, the piston was moved out at 1 $\mathrm{mm} / \mathrm{min}$. The temperature of the sample, $T_{\mathrm{s}}$, was controlled by a water bath in the range of 21 to $70{ }^{\circ} \mathrm{C}$. The heating rate was lower than $0.5^{\circ} \mathrm{C} / \mathrm{min}$, and the sample was kept at $T_{\mathrm{s}}$ for more than $20 \mathrm{~min}$ prior to the infiltration experiment. The measured sorption isotherm curves are shown in Figs. 1 and 2. The infiltration volume was taken as the difference between the volume changes of the samples and a reference system under the same pressure. The reference system consisted of only $6 \mathrm{~g}$ of deionized water in the same steel chamber. The effects of testing temperature on the infiltration pressure and the

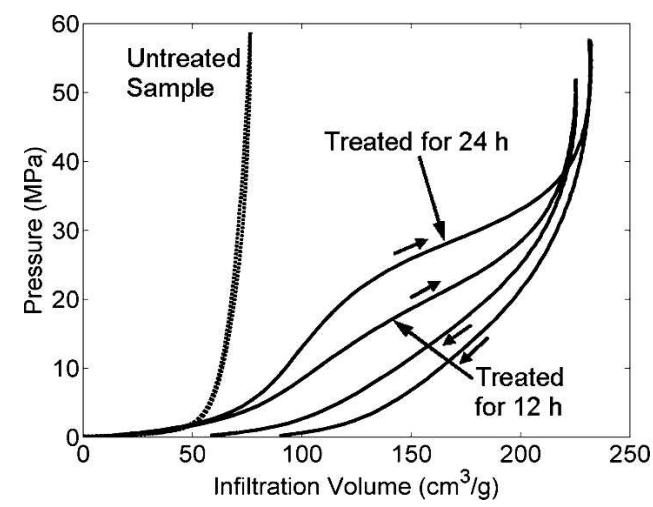

FIG. 1. Typical sorption isotherm curves of the acid-leached samples.

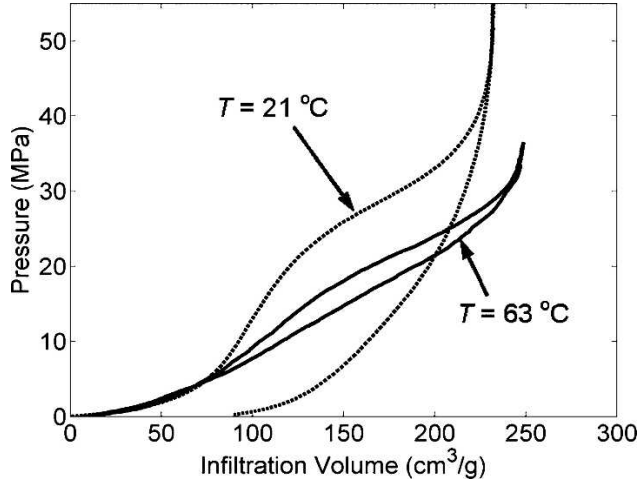

FIG. 2. Thermal effect on sorption isotherm of the $\beta$ zeolite sample acid leached for $24 \mathrm{~h}$.

hysteresis of sorption isotherm are shown in Fig. 3. The infiltration pressure is taken as the pressure at the point where the slope of sorption isotherm curve decreases by $50 \%$ from the low-pressure linear stage. It is for selfcomparison purpose only.

\section{RESULTS AND DISCUSSION}

Zeolites are widely used for controlling chemical reactions, primarily because of the high reactivity of the defect sites at their nanopore surfaces. ${ }^{22}$ The defects interact with guest species, and due to the large specific surface area the beneficial reactions can be largely promoted. The details of motion of confined gas and liquid molecules in nanopores, e.g., the differences in degree of hydrophobicity and effective pore volume, are still quite inadequately understood. In the current study, the defect density is modified to adjust the degree of hydrophobicity. As the zeolite $\beta$ sample is immersed in the nitric acid solution, the framework aluminum is hydrolyzed and removed, associated with the formation of silanols, as depicted in Fig. 4. As the Al-O bonds are broken and hydroxyl groups are formed, the aluminum groups $\left(\mathrm{AlO}_{3} \mathrm{Si}_{3}\right)$ are separated from the nanopore surface. ${ }^{23}$ They can diffuse out of the nanopores and eventually be

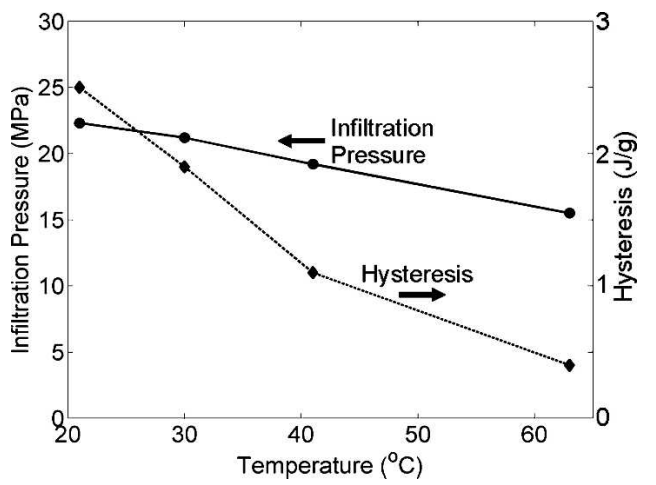

FIG. 3. The infiltration pressure and the hysteresis as functions of the testing temperature. The $\beta$ zeolite sample is acid-leach treated for $24 \mathrm{~h}$. 


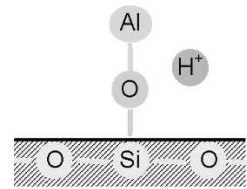

(a)

FIG. 4. Acid leaching process. (a) An initial defect site at nanopore surface. (b) The acid-leached surface. (c) The calcined surface.

removed during drying and washing. The hydroxyl sites are negatively charged; they are deactivated during the calcination process by silicon migration or condensation of surrounding $\mathrm{SiOH}$ groups. The calcined surface tends to be nonpolar and thus becomes more hydrophobic.

Even without the acid-leaching treatment, the zeolite $\beta$ sample exhibits hydrophobic characteristics in gas absorption analysis. In the liquid infiltration experiment, however, it is effectively hydrophilic. Immediately after the untreated zeolite powders are mixed with water, they are fully soaked, before the pressure-induced infiltration experiment is performed. As shown by the dashed line in Fig. 1, no matter how high the applied pressure is, no infiltration can be observed, because the nanopores have already been filled. The difference in effective degrees of hydrophobicity of zeolite in gas and liquid phases may be attributed to the confinement effect of nanopore walls and the unique chainlike structure of water molecules in nanopores, ${ }^{24}$ as well as the free-energy increase associated with breakage of hydrogen bonds among water molecules in bulk liquid phase and the formation of additional bonds at nanopore surfaces, ${ }^{25}$ the details of which are still under investigation.

After the zeolite $\beta$ sample is acid-leach treated for $12 \mathrm{~h}$, the sorption isotherm changes significantly. As the nanopore surface becomes hydrophobic, under atmosphere pressure water molecules do not infiltrate into the nanopores. With the increase in external pressure, the infiltration rate rises rapidly, and at the critical infiltration pressure, $p_{\text {in }} \approx 15 \mathrm{MPa}$, a plateau is formed in the sorption isotherm curve. In the following discussion, the infiltration pressure is defined as the pressure at the onset of infiltration, i.e., the intersection point of tangent lines of the low-pressure linear compression stage and the infiltration plateau. The accelerated infiltration and the presence of the critical $p_{\text {in }}$ are in agreement with the result of a recent molecular dynamics (MD) simulation. ${ }^{26}$ The width of the infiltration plateau is about $100 \mathrm{~mm}^{3} / \mathrm{g}$. The total infiltration volume, including the infiltration plateau and the low-pressure linear stage, is close to 150 $\mathrm{mm}^{3} / \mathrm{g}$, smaller than the specific nanopore volume determined by the gas absorption analysis, as it should be, since the van der Waals distance between confined water molecules and nanopore walls takes a considerable portion of the nanopore volume. When the nanopores are filled, the system becomes nearly incompressible. Note that the infiltration process is irreversible. During unloading, the system volume starts to recover only when the pressure is much lower than the loading path. The system hysteresis, which is measured by the area enclosed by the sorption isotherm curve, is about $1.5 \mathrm{~J} / \mathrm{g}$.

As the acid-leaching treatment time increases to $24 \mathrm{~h}$, it is evident that the degree of hydrophobicity rises. The infiltration pressure increases to $22 \mathrm{MPa}$ by nearly $50 \%$. Clearly, as more defect sites are deactivated, the local silica-to-alumina ratio at nanopore surface is higher. If the treatment time is further increased, the value of $p_{\text {in }}$ does not vary significantly, suggesting that the surface structure has reached the saturation status. The width of infiltration plateau is still close to $150 \mathrm{~mm}^{3} / \mathrm{g}$, since it is dominated by the nanoporous structure. The hysteresis is more pronounced. The dissipated energy in the loadingunloading cycle increases to $2.5 \mathrm{~J} / \mathrm{g}$, more than $60 \%$ higher than that of the sample treated for $12 \mathrm{~h}$. The increase in hysteresis should be associated with the increase in infiltration pressure and the decrease in defiltration pressure. Note that the decrease in defiltration pressure is somewhat contradictory to the increase in $p_{\text {in }}$, since the latter is the driving force of defiltration. This phenomenon may be attributed to the increase in lattice resistance caused by the increase in silica content and the variation in morphology. ${ }^{25-27}$

Figure 2 shows that the sorption isotherm of the acidleach treated $\beta$ zeolite is highly dependent on temperature. When the temperature increases from 21 to $63^{\circ} \mathrm{C}$, the infiltration and defiltration behaviors vary considerably. First, the slope of the low-pressure linear compression stage decreases, indicating that under the same pressure the infiltration rate increases with temperature, probably due to the promotion effect of thermal motion of liquid molecules; that is, as the thermal vibration is more pronounced, the average time it takes for a liquid molecule to overcome the energy barrier of nanopore wall is reduced. ${ }^{28}$ Second, at a higher temperature, the slope of the infiltration plateau is relatively small while the infiltration pressure is much lower. Since in the temperature range under investigation, the nanopore surface structure is quite stable, the variation in $p_{\text {in }}$ should be related to the decrease in effective polarity of water phase. As thermal motion of $\mathrm{H}_{2} \mathrm{O}$ is promoted, the confined liquid tends to be more compatible with the nonpolar solid surface, and consequently the infiltration becomes easier. ${ }^{28}$ Third, compared with the room-temperature curve, as the temperature is $63{ }^{\circ} \mathrm{C}$ the difference between infiltration and defiltration pressures is much smaller. The specific dissipated energy is reduced to $0.4 \mathrm{~J} / \mathrm{g}$; that is, the infiltration process is more reversible. When temperature rises, the effect of lattice resistance of nanopore wall to molecules of confined liquid should be reduced. It is also easier for the vapor/gas phase, which may exist in the form of nanobubbles, to grow and eventually "repel" the 
liquid phase out of the nanopores. ${ }^{25}$ Both effects tend to promote liquid defiltration. The temperature influence on the infiltration pressure and the system hysteresis is more clearly shown in Fig. 3. It can be seen that the thermal effect is quite linear, suggesting that the temperature change does not cause any new mechanisms of liquid infiltration and defiltration.

\section{CONCLUDING REMARKS}

As an effectively hydrophilic $\beta$ zeolite is acid leached and calcined, it becomes hydrophobic and pressureinduced infiltration can take place. As the pressure is relatively low, the liquid infiltration is relatively slow, which is dominated by thermal diffusion. When the pressure reaches a critical value, the infiltration is accelerated, until the nanopores are filled. As the acid-leaching treatment time increases, both of the degree of hydrophobicity and the system hysteresis become larger. If temperature increases, the infiltration rate at lowpressure linear compression stage increases and the critical infiltration pressure decreases, indicating that the energy barrier of nanopore surface is reduced. The reversibility of liquid infiltration is improved.

\section{ACKNOWLEDGMENT}

This work was supported by The National Science Foundation under Grant No. CMS-0623973.

\section{REFERENCES}

1. M. Simion, I. Kleps, T. Neghina, A. Angelescu, M. Miu, A. Bragaru, M. Danila, E. Condac, M. Costache, and L. Savu: Nanoporous silicon matrix used as biomaterial. J.Allovs Compd. 434, 830 (2007).

2. A. Dabrowski: Adsorption-from theory to practice. $\underline{A d v \text {. Colloid }}$ Interface Sci. 93, 135 (2001).

3. J.A. Ritter and A.D. Ebner: State-of-the-art adsorption and membrane separation processes for hydrogen production in the chemical and petrochemical industries. Sep. Sci. Technol. 42, 1123 $\underline{(2007)}$.

4. V.K. Punyamurtula and Y. Qiao: Infiltration of pressurized promoter solutions in a mesoporous silica. Microporous Mesoporous Mater. 103, 35 (2007).

5. A. Han and Y. Qiao: Suppression effect of liquid composition on defiltration of nanofluids in lyophobic environment. J.Phvs. D: Appl. Phys. 40, 3436 (2007).

6. X. Kong and Y. Qiao: An electrically controllable nanoporous smart system. J. Appl. Phvs. 99, 064313 (2006).

7. A. Han and Y. Qiao: Infiltration pressure of a nanoporous liquid spring modified by an electrolyte. J. Mater. Res. 22, 644 (2007).

8. V.D. Borman, A.M. Crekhov, and V.I. Troyan: Investigation of the percolation transition in a nonwetting liquid-nanoporous medium system. J. Exp. Theor. Phys. 91, 170 (2000).

9. S. Reichman, A. Ulus, and E. Peled: PTFE-based solid polymer electrolyte membrane for high-temperature fuel-cell applications. J. Electrochem. Soc. 154, B327 (2007).

10. J.K. Holt, H.G. Park, Y.M. Wang, M. Stadermann, A.B. Artyukhin, C.P. Grigoropoulos, A. Noy, and O. Bakajin: Fast mass transport through sub-2-nanometer carbon nanotubes. Science 312, 1034 $\underline{(2006)}$.

11. V. Eroshenko, R.C. Regis, M. Soulard, and J. Patarin: Energetics-A new field of application for hydrophobic zeolites. $\underline{\text { J. Am. }}$ Chem. Soc. 123, 8129 (2001).

12. T. Martin, B. Lefevre, D. Brunel, A. Galarneau, F. di Renzo, F. Fajula, P. Gobin, J.F. Quinson, and G. Vigier: Dissipative water intrusion in hydrophobic MCM-41 type materials. Chem. Commun. 24 (2002).

13. F.B. Surani and Y. Qiao: Energy absorption of a polyacrylic acid partial sodium salt modified nanoporous system. J.Mater. Res. 21. 1327 (2006).

14. X. Kong, F.B. Surani, and Y. Qiao: Effects of addition of ethanol on the infiltration pressure of a mesoporous silica. J.Mater. Res. 20, 1042 (2005).

15. Y. Qiao, V.K. Punyamurtula, A. Han, X. Kong, and F.B. Surani: Temperature dependence of working pressure of a nanoporous liquid spring. Appl. Phvs. Lett. 89, 251905 (2006).

16. A. Han and Y. Qiao: Thermal effects on infiltration of a solubility sensitive volume memory liquid. Philos. Mag. Lett. 87.25 (2007).

17. B.D. Zdravkov, J.J. Cermak, M. Sefara, and J. Janku: Pore classification in the characterization of porous materials-A perspective. Cent. Euro. J. Chem. 5, 385 (2007).

18. J.C. Jansen: Introduction to Zeolite Science and Practice (Elsevier Science, 1991).

19. M.R. Apelian, A.S. Fung, and G.J. Kennedy: Dealumination of zeolite $\beta$ via dicarboxylic acid treatment. J.Phvs. Chem. 100. 16577 (1996).

20. M. Muller, G. Harvey, and R. Prins: Comparison of the dealumination of zeolites beta, mordenite, ZSM- 5 and ferrierite by thermal treatment, leaching with oxalic acid and treatment with $\mathrm{SiCl} 4$ by ${ }^{1} \mathrm{H},{ }^{29} \mathrm{Si}$ and ${ }^{27} \mathrm{Al}$ MAS NMR. Microporous Mesoporous Mater. 34, 135 (2000).

21. D.M. Roberge, H. Hausmann, and W.F. Hölderich: Dealumination of zeolite beta by acid leaching: A new insight with twodimensional multi-quantum and cross polarization ${ }^{27} \mathrm{Al}$ MAS NMR. Phys. Chem. Chem. Phys. 4, 3128 (2002).

22. M.A. Camblor, A. Corma, and S. Iborra: Beta zeolite as a catalyst for the preparation of alkyl glucoside surfactants: The role of crystal size and hydrophobicity. J. Catal. 172, 76 (1997).

23. C. Coutanceau, J.M. Da Silva, and M.F. Alvarez: Dealumination of zeolites. Part VII. Influence of the acid treatment of a HBEA zeolite on the framework composition and on the porosity. J. Chim. Phys. 94, 765 (1997).

24. H. Pehlivan, F. Ozmihcl, and F. Tihmınlıglu: Water and water vapor sorption studies in polypropylene-zeolite composites. J. Appl. Polv. Sci. 90, 3069 (2003).

25. Y. Qiao, G. Cao, and X. Chen: Effects of gas molecules on nanofluidic behaviors. J. Am. Chem. Soc. 129, 2355 (2007).

26. A. Han, X. Kong, and Y. Qiao: Pressure induced infiltration in nanopores. J. Appl. Phys. 100, 014308 (2006).

27. J. Stelzer, M. Paulus, and M. Hunger: Hydrophobic properties of all-silica zeolite beta. Microporous Mesoporous Mater. 22, 1 (1998).

28. P. Demontis, G. Stara, and G.B. Suffritti: Behavior of water in the hydrophobic zeolite silicalite at different temperatures. A molecular dynamics study. J. Phys. Chem. B 107, 4426 (2003). 